\title{
Safety Effects of Freeway Hard Shoulder Running
}

\author{
Jaisung Choi ${ }^{1}$, Richard Tay ${ }^{2, *}{ }^{\mathbb{C}}$, Sangyoup Kim ${ }^{3}$, Seungwon Jeong ${ }^{1}$, Jeongmin Kim ${ }^{4}$ \\ and Tae-Young Heo ${ }^{5}$ iD \\ 1 Department of Transportation Engineering, University of Seoul, Seoul, Korea \\ 2 School of Business IT \& Logistics, RMIT University, Melbourne 3000, Australia \\ 3 Department of Regional Development Research, Land Use \& Transportation Research, Jeonbuk Institute, \\ Jeollabuk-do, Korea \\ 4 AI \& Bigdata Research Team, The Korea Transport Institute, Sejong, Korea \\ 5 Department of Information Statistics, Chungbuk National University, Cheongju, Korea \\ * Correspondence: rtay888@gmail.com; Tel.: +61-3-9925-1438
}

Received: 6 August 2019; Accepted: 29 August 2019; Published: 2 September 2019

check for updates

Featured Application: Hard shoulder running (HSR) has been increasingly used in recent years as a more sustainable way to alleviate congestion and increase the efficiency of freeways in many countries. We found that freeways experienced more crashes after installing HSR, but most of the crashes were less severe. Hence, caution should be exercised when designing and implementing hard shoulder running to reflect the trade-off between improvements in efficiency and a reduction in safety. Also, HSR installation on lengthy freeways with two travel lane configurations (without HSR) should be avoided.

\begin{abstract}
Hard shoulder running (HSR) has been increasingly used as a sustainable and viable way to increase road capacity. This study investigated the safety effect of HSR on freeways in South Korea using the empirical Bayes method. This study found an increase in the total number of crashes. In terms of crash severity, a higher proportion of crashes (25.3\%) on 2(3)-lane sections were found to be serious (involving injuries and/or fatalities) compared to those on 4(5)-lane sections (3.6\%). Also, a positive relationship was found between the length of the hard shoulder running and changes in crash frequencies. Thus, hard shoulder running on lengthy 2(3)-lane freeways should be avoided.
\end{abstract}

Keywords: hard shoulder running; crashes involving injuries and/or fatalities; empirical Bayes method

\section{Introduction}

\subsection{Background}

Traffic congestion increases travel time and time wasted in delays, which will incur an economic cost to both road users and society as a whole [1]. Like many developed countries, South Korea experiences frequent and vocal driver complaints resulting from freeway traffic congestion [2-4]. To deal with driver complaints and the potential economic losses, the South Korean government has dedicated US\$27 billion over 10 years to freeway operation improvement programs, which include roadway improvements, roadway operation improvements, ramp control, managed lanes, and high-occupancy vehicle treatments. These efforts have paid off and contributed to a steady decline in traffic congestion [5-8]. Nevertheless, transportation engineers are still seeking more ways to increase the capacity and efficiency of the road network, especially by using more sustainable ways to increase the utilization of existing road infrastructures.

One way to increase highway capacity and efficiency using a more sustainable approach is to make greater use of the freeway shoulders. The cross section of an existing freeway is modified by 
converting all or part of the shoulder into an additional lane and adjustment of the width of adjacent travel lanes is sometimes required as well. The lane created by this method is called hard shoulder running (HSR). Compared to the traditional method of increasing capacity by building more roads or constructing more lanes, HSR can be considered more sustainable because it utilizes the existing road shoulder during peak traffic hours to increase the road capacity. HSR has been increasingly used in Europe and North America to mitigate freeway congestion in a more sustainable way [9-12]. Also, compared with roadway expansion, which usually costs about US\$13.6 million per km in South Korea, a hard shoulder lane costs only about US $\$ 0.58$ million per km $[13,14]$. HSR was first adopted in South Korea a decade ago and is today gaining recognition within the general public as a favorable, low-cost alternative to tackling the congestion problem $[15,16]$.

On the other hand, transportation engineers in South Korea are divided in terms of their support for this design. The biggest concern for some engineers is a potential decrease in road safety. The purpose of having a road shoulder is to serve as an emergency stopping lane for motorists and to allow for recovery of errant vehicles before a potential collision occurs [17]. Its omission may therefore result in more frequent vehicle crashes [18-20]. The Korea Expressway Corporation (KEC), the central authority for operating the freeway system, acknowledges that vehicle crashes in freeway sections with HSR have increased [21]. As shown in the lower half of Figure 1, there were a total of 350 vehicle crashes in the three years before the introduction of HSR in the seven freeway corridors, but the number of vehicle crashes increased to 493 in the three years after the introduction of HSR in the same freeway corridors [21]. On the other hand, as shown in the top half of the figure, the number of crashes for the entire freeway (with and without HSR) has fallen for the corresponding before and after periods.

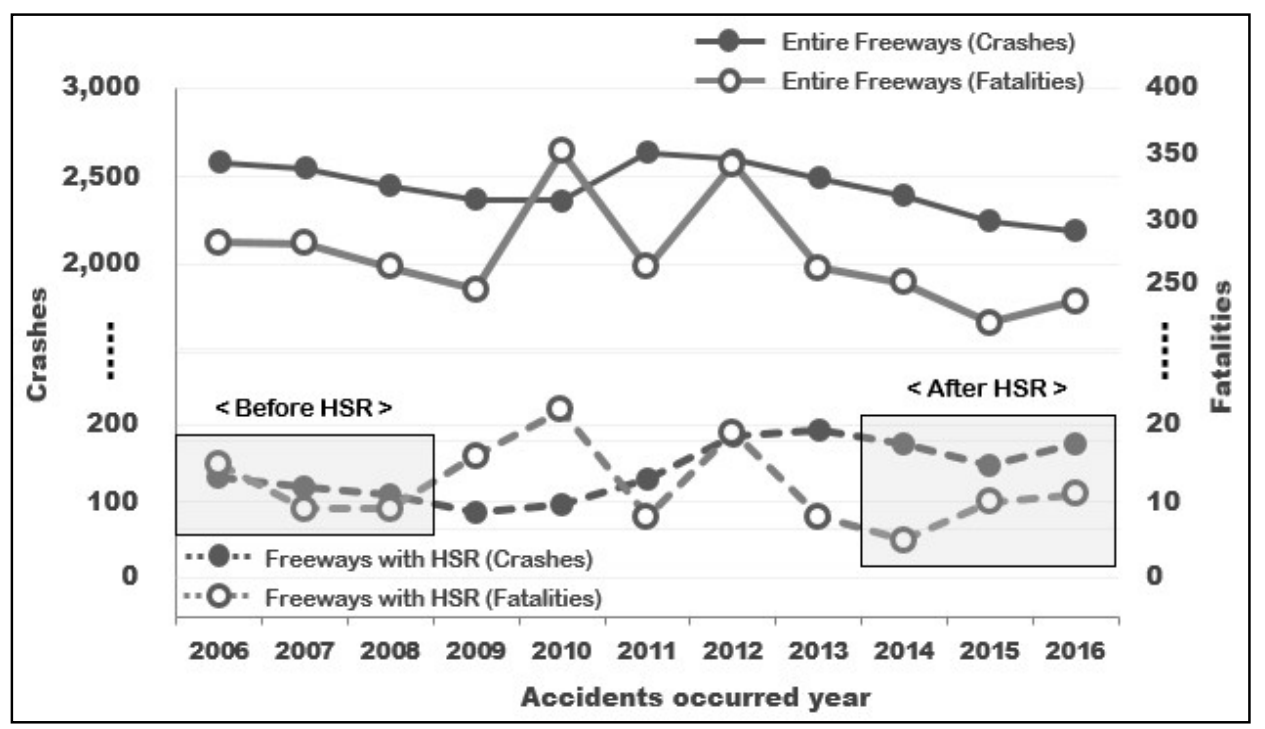

Figure 1. Annual crash frequency before and after hard shoulder running.

Nevertheless, public support for the application of HSR remains strong in South Korea and proponents argue that there is no valid statistical evidence of more crashes with HSR in South Korea; also, there is international evidence that suggests it does not increase crashes [10]. Moreover, as shown in Figure 2, the repaved shoulder in South Korea is usually equipped with a lane control system that should mitigate safety concerns. Also, part of the increase in vehicle crashes could be attributed to an increase in traffic flow from an average of 119,793 vehicles/day to 134,480 vehicles/day. The increase in travel, whether for work or leisure, would contribute to the economy and improve the quality of life for users. 


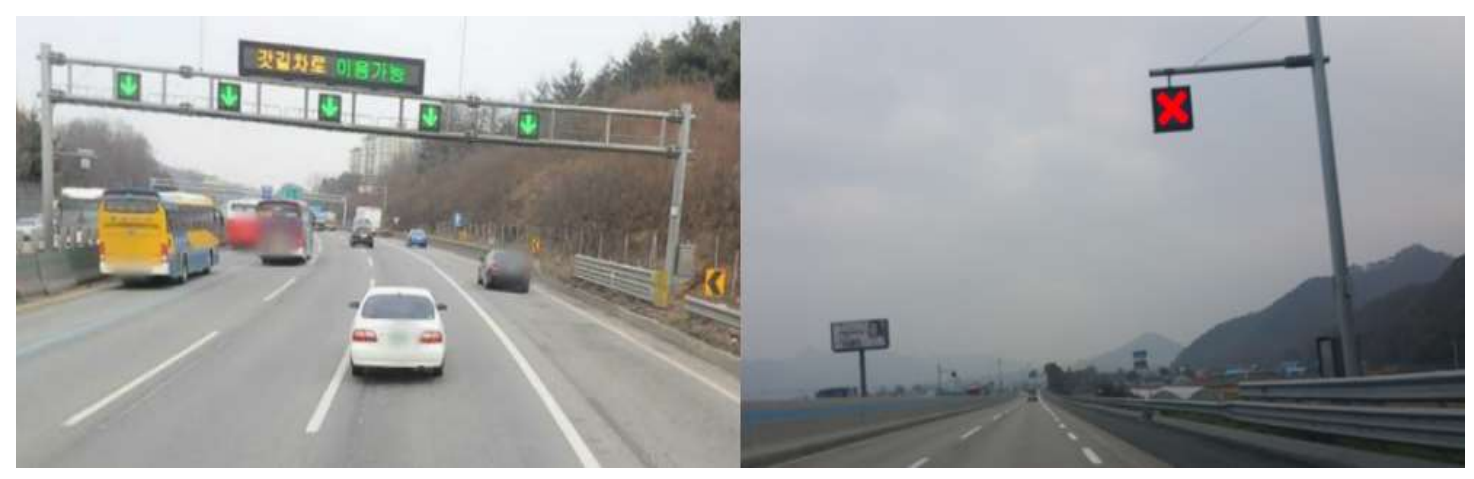

Figure 2. Hard shoulder running in South Korea.

The authors' review of the literature suggests that the international evidence on HSR is mixed [9-12,18-20,22-24]. More importantly, conflicting results and views have yet to be reconciled $[19,20,24]$. "Practicing traffic engineers generally believe that decreased congestion resulting from hard shoulder running is associated with some unspecified degree of improved safety; yet, the majority opinion among researchers is that accident rates increase with an increase in the number of lanes, even if full shoulders are provided. Despite many years of modern road building, these conflicting views have not been reconciled" [19]. Therefore, more studies need to be conducted to better understand the safety effect of this design feature.

\subsection{Safety Effects of HSR in South Korea}

There are several reasons why HSR might lead to an increased crash risk. This study will focus on three possible driver-geometric explanations that are more relevant to South Korea. The first reason is drivers' low familiarity with HSR. Since many freeway motorists in South Korea do not often experience hard shoulder running, they may not be familiar with driving within this new cross-sectional design. The general look and feel of a road and roadside environment have significant effects on road users' attention, the routes they choose, and the speeds at which they choose to drive [25-27]. Therefore, freeway motorists' lack of familiarity with HSR design may contribute to more driving errors [19].

A second reason is the poor lane positioning of vehicles in HSR [28-31]. A reduction or elimination of shoulders will potentially have an impact on the lane positioning of vehicles. Based on the results of his earlier study, one researcher recommended a two-foot minimum shoulder width for a concrete median barrier [32]. In one of the few studies conducted in South Korea, it was found that the design criteria for satisfying the minimum $1.25 \mathrm{~m}$ shoulder width had a significant impact on crash occurrences [33]. Since hard shoulder running is built with a shoulder width of less than $0.5 \mathrm{~m}$ in South Korea, drivers may have difficulty keeping proper lane positioning and thus, presumably, experience more crashes.

A third possible reason is the unpredictability of drivers' speed before and after the implementation of HSR. One study found that the cues drivers used to select their driving speed on highways were derived mostly from peripheral vision [34]. In HSR, the peripheral vision may be different from that on normal freeway sections, because the lateral clearance on the right side of the freeway travel lane is greatly reduced or no longer exists. Clearly, any deterioration in drivers' ability to estimate the correct speed will increase their crash risks.

In summary, we have sufficient reasons to hypothesize that the vehicle crashes occurring in HSR in South Korea may be associated with inappropriate driver performance due to low familiarity, the elimination of shoulder width, and changed peripheral vision.

\subsection{Objectives of Study}

The aim of this study is to evaluate the safety effect of HSR by applying the EB (empirical Bayes) methodology to crash data from South Korea collected before and after the HSR trials. More specifically, 
this study will determine whether HSR will increase drivers' crash risk, with a special focus on the safety effect of cross-sectional design elements, such as the number of lanes and length of HSR. In addition to these design elements, mean speed, traffic volume, and truck percentage are examined in the safety performance function, because these values are stable and reliable predictors of crash occurrences [35-38]. Moreover, this study will add to the literature because of the differences in design, traffic conditions, and reactions of drivers in South Korea and the use of the EB method, which is more rigorous than what was used in some previous studies on the safety effects of HSR.

\section{Methodology}

This study uses the EB method to evaluate the safety effect of HSR and to identify the factors contributing to crashes. The existing literature indicates that three years is the most common choice for the timeframe for before-after collision studies, because traffic flow for three years is unlikely to have changed a great deal [39] and this period is expected to provide a relatively reliable sample. In December 2015, there were eight freeway corridors with HSR [14], in which 32 different HSR sections were constructed. The total length was $222.6 \mathrm{~km}$. Of the 32 sections, this study selected 22 HSR sections with a total length of $162.15 \mathrm{~km}$, for which complete data were available (see Table 1). In terms of the number of traffic lanes, the selected sites consisted of 14 eight-lane freeways, one six-lane freeway, and seven four-lane freeways. Their construction period ranged from 2009 to 2013.

Table 1. Traffic and roadway factors, before and after HSR.

\begin{tabular}{|c|c|c|c|c|c|c|c|c|c|c|c|c|}
\hline \multirow[b]{2}{*}{ Site } & \multirow[b]{2}{*}{$\begin{array}{l}\text { Length } \\
(\mathbf{k m})\end{array}$} & \multirow[b]{2}{*}{$\begin{array}{l}\text { Lanes per } \\
\text { Way* }\end{array}$} & \multicolumn{4}{|c|}{ Before HSR (2006-2008) } & \multicolumn{6}{|c|}{ After HSR (2014-2016) } \\
\hline & & & AADT & $\begin{array}{c}\text { Ave. } \\
\text { Speed } \\
(\mathrm{km} / \mathrm{h})\end{array}$ & Crashes & $\begin{array}{l}\text { Crashes per } \\
100 \mathrm{~m} \text { VKM }\end{array}$ & $\begin{array}{c}\text { Lane } \\
\text { Width } \\
\text { (m) }\end{array}$ & $\begin{array}{l}\text { Shoulder } \\
\text { Width (m) }\end{array}$ & AADT & $\begin{array}{c}\text { Ave. } \\
\text { Speed } \\
(\mathrm{km} / \mathrm{h})\end{array}$ & Crashes & $\begin{array}{l}\text { Crashes per } \\
100 \mathrm{~m} \text { VKM }\end{array}$ \\
\hline 1 & 6.7 & $4(5)$ & 53,500 & 93.2 & 12 & 3.1 & 3.50 & 2.85 & 60,400 & 95.2 & 26 & 5.9 \\
\hline 2 & 8.4 & $4(5)$ & 50,600 & 95.1 & 20 & 4.5 & 3.58 & 2.87 & 57,100 & 96.1 & 42 & 8.0 \\
\hline 3 & 11.6 & $4(5)$ & 68,000 & 96.6 & 34 & 3.9 & 3.55 & 2.81 & 78,200 & 96.6 & 68 & 6.8 \\
\hline 4 & 10.7 & $4(5)$ & 67,000 & 89.0 & 25 & 3.2 & 3.63 & 2.74 & 75,000 & 93.0 & 26 & 3.0 \\
\hline 5 & 5.1 & $4(5)$ & 79,200 & 84.0 & 31 & 7.0 & 3.56 & 2.78 & 78,500 & 83.0 & 11 & 2.5 \\
\hline 6 & 5.1 & $4(5)$ & 92,100 & 89.6 & 15 & 2.9 & 3.57 & 2.87 & 91,300 & 88.6 & 16 & 3.1 \\
\hline 7 & 5.1 & $4(5)$ & 75,100 & 94.6 & 17 & 4.1 & 3.55 & 2.95 & 79,500 & 93.6 & 12 & 2.7 \\
\hline 8 & 3.9 & $4(5)$ & 79,900 & 88.0 & 10 & 2.9 & 3.67 & 2.83 & 84,700 & 91.0 & 2 & 0.6 \\
\hline 9 & 6.8 & $4(5)$ & 67,400 & 91.7 & 23 & 4.6 & 3.60 & 2.87 & 77,800 & 95.7 & 11 & 1.9 \\
\hline 10 & 11.6 & $4(5)$ & 63,400 & 75.0 & 21 & 2.6 & 3.52 & 2.80 & 77,900 & 79.0 & 67 & 6.8 \\
\hline 11 & 8.4 & $4(5)$ & 66,800 & 78.5 & 17 & 2.8 & 3.63 & 2.77 & 82,100 & 78.5 & 66 & 8.7 \\
\hline 12 & 6.7 & $4(5)$ & 63,300 & 75.6 & 13 & 2.8 & 3.62 & 2.91 & 77,800 & 77.6 & 33 & 5.8 \\
\hline 13 & 2.9 & $4(5)$ & 80,100 & 90.5 & 5 & 2.0 & 3.52 & 2.81 & 88,000 & 90.7 & 3 & 1.1 \\
\hline 14 & 2.1 & $4(5)$ & 145,000 & 85.1 & 6 & 1.8 & 3.49 & 2.76 & 134,100 & 89.1 & 1 & 0.3 \\
\hline 15 & 11.8 & 2(3) & 26,300 & 89.9 & 11 & 3.2 & 3.51 & 2.91 & 29,500 & 93.9 & 14 & 3.7 \\
\hline 16 & 20.0 & 2(3) & 23,800 & 94.6 & 31 & 5.9 & 3.57 & 2.84 & 27,300 & 95.6 & 33 & 5.5 \\
\hline 17 & 6.5 & 2(3) & 44,800 & 92.4 & 6 & 1.9 & 3.69 & 2.93 & 49,000 & 94.4 & 4 & 1.1 \\
\hline 18 & 6.6 & $3(4)$ & 20,700 & 101.1 & 6 & 4.0 & 3.63 & 2.94 & 21,900 & 104.1 & 5 & 3.2 \\
\hline 19 & 2.8 & 2(3) & 23,000 & 80.3 & 6 & 8.5 & 3.61 & 2.71 & 26,000 & 80.3 & 6 & 5.0 \\
\hline 20 & 9.0 & 2(3) & 29,200 & 94.9 & 20 & 6.9 & 3.63 & 3.13 & 30,200 & 94.9 & 21 & 5.7 \\
\hline 21 & 5.2 & 2(3) & 49,000 & 88.9 & 3 & 1.1 & 3.46 & 2.85 & 52,500 & 90.9 & 12 & 4.0 \\
\hline 22 & 5.2 & 2(3) & 47,700 & 86.7 & 18 & 6.6 & 3.52 & 2.84 & 51,000 & 86.6 & 20 & 6.9 \\
\hline
\end{tabular}

Note: * 4(5) lanes indicates that a site has four lanes without a hard shoulder and five lanes with a hard shoulder.

In applying the EB method for before-after studies, one critical element is the availability of a safety performance function (SPF). An SPF is an equation/regression model that is used to predict the average number of crashes per year at a location as a function of exposure and geometric design elements (number of lanes, length of section, etc.). While the Highway Safety Manual [17] has specified SPFs for typical roadway sections developed from data in the USA, researchers can also develop SPFs that relate directly to their site-specific conditions. For this study, an SPF was developed using a select set of reference sites that have similar traffic and geometric conditions to those of the treatment sites. Therefore, this study selected 22 freeway sites located immediately upstream and downstream of a HSR, as well as 86 freeway sections located on the same freeways but farther away from the HSR sites (see Table 2). Data on these sites were used in the estimation of the safety performance function used in the EB method. 
Table 2. Summary statistics of reference sites.

\begin{tabular}{cccc}
\hline Variable & Description & Mean & Std Dev \\
\hline A & Annual average daily traffic (veh/day) & $80,792.97$ & $55,698.64$ \\
T & Daily average truck volume (veh/day) & 4373.10 & 3267.31 \\
V & Average speed $(\mathrm{km} / \mathrm{h})$ & 98.41 & 7.45 \\
N & Number of lanes & 2.86 & 0.91 \\
L & Length of site $(\mathrm{km})$ & 7.98 & 4.75 \\
LW & Lane width $(\mathrm{m})$ & 3.60 & 0.03 \\
SW & Shoulder width $(\mathrm{m})$ & 3.62 & 0.05 \\
\hline
\end{tabular}

Lastly, to determine the various safety effects of deploying HSR in freeways, this study examined its effects on serious crashes (those involving injuries and/or fatalities), property damage only (PDO) crashes, and total crashes. This approach was required because the crash impact from each independent variable on the dependent variables would be different in the safety performance functions. Moreover, it would also provide useful information on the effects of HSR on crashes of different severity levels.

\subsection{Data}

The motor vehicle crash data used in this study were extracted from vehicle crash data collected by KEC. The data about the HSR in this study were provided by the Korean Expressway Corporation. The data included information on total coverage length, opening dates, and roadway conditions, as well as traffic and vehicle factors. The traffic flow data for the selected sites were provided by an Internet portal site that was being operated by the KEC. They applied a vehicle detection system to collect real-time traffic flow information. To be consistent with the existing literature, the freeway lengths used were $0.3-0.5 \mathrm{~km}$ for spot speed analysis and $2.0-3.0 \mathrm{~km}$ for segment analysis [39]. Traffic flow characteristics and roadway features for the before and after conditions are listed in Table 1.

\subsection{Empirical Bayes Method}

The aim of this study was to evaluate the safety effect of HSR by applying the EB methodology [40, 41] to crash data from South Korea for before and after HSR trials. The EB method is commonly used by transportation safety analysts for conducting different types of safety analyses, such as before-after studies and hotspot analyses [42-46]. It enables researchers to control for several critical factors such as regression-to-the-mean effect, long-term trends, and exogenous changes in traffic volume [47].

In order to apply the EB method, we need to develop a safety performance function. The negative binomial model is selected because of the presence of overdispersion in the data. The general form of the negative binomial model is given below:

$$
\begin{gathered}
p\left(Y_{i}=y_{i}\right)=\frac{\Gamma\left(y_{i}+a^{-1}\right)}{y ! \Gamma\left(a^{-1}\right)}\left(\frac{a \mu_{i}}{1+a \mu_{i}}\right)^{y_{i}}\left(\frac{1}{1+a \mu_{i}}\right)^{a^{-1}} \\
\mu_{i}=\exp \left(\beta_{0}+\beta_{1} x_{i 1}+\beta_{2} x_{i 2}+\ldots+\beta_{k} x_{i k}\right),
\end{gathered}
$$

where

$y_{i}$ is the crash count at site $i$;

$\mu_{i}$ is the expected number of crashes at site $i$;

$\beta_{0}, \beta_{1}, \beta_{\mathrm{k}}$ are the parameters to be estimated;

$x_{i 1}, \ldots, x_{i k}$ are the explanatory variables for neighborhood $i$;

$\alpha$ is the dispersion parameter.

The EB method is then applied to determine the expected crash occurrences:

$$
\mathrm{k}=\lambda \mathrm{w}+(1-\mathrm{w}) \mathrm{K}
$$




$$
\mathrm{w}=1 /(1+\lambda \alpha)
$$

where

$\mathbf{k}$ is the expected number of crashes before treatment;

$\lambda$ is the model-predicted number of crashes before treatment;

$\mathbf{w}$ is the weight given to the model-predicted number of crashes;

$\mathbf{K}$ is the recorded number of crashes before treatment.

\section{Results}

Estimates for each of three safety performance functions are given in Table 3. As expected, traffic volume, share of truck traffic, average speed, number of lanes, and length of road sections all have a significant effect on the total number of crashes and number of property damage only crashes. However, only truck traffic and section length have a significant effect on the number of serious crashes. On the other hand, lane width and shoulder width have been found to be insignificant.

Table 3. Safety performance function.

\begin{tabular}{ccccccc}
\hline \multirow{2}{*}{ Dependent Variables } & & \multicolumn{5}{c}{ Independent Variables } \\
\cline { 3 - 7 } & & $\mathbf{L n}(\mathbf{A})$ & $\mathbf{L n}(\mathrm{T})$ & $\mathbf{L n}(\mathrm{V})$ & $\mathbf{N}$ & $\mathrm{L}$ \\
\hline \multirow{2}{*}{ Total crashes } & coefficients & 0.938 & 0.430 & 2.567 & -0.454 & 0.123 \\
& $p$-value & 0.010 & 0.032 & 0.041 & 0.040 & $<0.001$ \\
\hline \multirow{2}{*}{ Serious crashes } & coefficients & & 0.627 & & & 0.131 \\
& $p$-value & & $<0.001$ & & & $<0.001$ \\
\hline \multirow{2}{*}{ PDO crashes } & coefficients & 1.188 & 0.462 & 3.013 & -0.654 & 0.113 \\
& $p$-value & 0.002 & 0.030 & 0.026 & 0.005 & $<0.001$ \\
\hline
\end{tabular}

Table 4 shows the estimated long-term expected numbers of crashes for the 22 freeway sites with HSR versus the actual crash numbers in those sites. As expected, increases were found for all crash types in aggregate (the sum of all 22 sites). However, the increase in the number of serious crashes (those involving injuries and/or fatalities) was relatively small $\left(\overline{x_{s}}=4.5-4.4\right)$ compared to property damage only $\left(\overline{x_{p d o}}=17.9-15.5\right)$ and total crashes $\left(\overline{x_{t}}=22.4-19.1\right)$. Thus, freeway motorists operating on HSR appeared to be involved in crashes more frequently, but most of the crashes were less severe. Part of the increase may result from drivers' risky behaviors within HSR areas. Some of the drivers may be unfamiliar with the changed freeway driving environment due to HSR and may engage in unexpected vehicle maneuvering.

Table 4. Estimated crash effects of HSR.

\begin{tabular}{ccccccc}
\hline \multirow{2}{*}{ Site } & \multicolumn{3}{c}{$\begin{array}{c}\text { Actual Crashes } \\
\text { (Crashes/3 years) }\end{array}$} & \multicolumn{3}{c}{$\begin{array}{c}\text { Expected Crashes } \\
\text { (Crashes/3 years) }\end{array}$} \\
\cline { 2 - 7 } & Total & Serious & PDO & Total & Serious & PDO \\
\hline 1 & 26 & 8 & 18 & 21.4 & 6.9 & 14.9 \\
2 & 42 & 0 & 42 & 33.5 & 1.0 & 33.1 \\
3 & 68 & 0 & 68 & 55.9 & 1.7 & 55.2 \\
4 & 26 & 11 & 15 & 21.7 & 9.2 & 12.8 \\
5 & 11 & 4 & 7 & 9.4 & 3.6 & 6.1 \\
6 & 16 & 6 & 10 & 14.2 & 5.4 & 9.1 \\
7 & 12 & 1 & 11 & 11 & 1.1 & 10.1 \\
8 & 2 & 0 & 2 & 2.1 & 0.1 & 2.1 \\
9 & 11 & 4 & 7 & 10.3 & 3.8 & 6.6 \\
\hline
\end{tabular}


Table 4. Cont.

\begin{tabular}{ccccccc}
\hline \multirow{2}{*}{ Site } & \multicolumn{3}{c}{$\begin{array}{c}\text { Actual Crashes } \\
\text { (Crashes/3 years) }\end{array}$} & \multicolumn{3}{c}{$\begin{array}{c}\text { Expected Crashes } \\
\text { (Crashes/3 years) }\end{array}$} \\
\cline { 2 - 7 } & Total & Serious & PDO & Total & Serious & PDO \\
\hline 10 & 67 & 14 & 53 & 59.1 & 13.2 & 46.7 \\
11 & 66 & 7 & 59 & 59.1 & 6.8 & 52.7 \\
12 & 33 & 5 & 28 & 30 & 4.9 & 25.4 \\
13 & 3 & 0 & 3 & 3 & 0.4 & 2.8 \\
14 & 1 & 1 & 0 & 2.6 & 1.3 & 1.8 \\
15 & 14 & 5 & 9 & 12.6 & 4.7 & 8.7 \\
16 & 33 & 20 & 13 & 29.3 & 16.7 & 14.2 \\
17 & 4 & 1 & 3 & 4.7 & 1.6 & 3.8 \\
18 & 5 & 1 & 4 & 5 & 1.3 & 4.1 \\
19 & 4 & 0 & 4 & 2.8 & 0.3 & 2.7 \\
20 & 17 & 7 & 10 & 14.7 & 6.2 & 9.5 \\
21 & 12 & 2 & 10 & 10.1 & 3.0 & 10.6 \\
22 & 20 & 2 & 18 & 7.1 & 3.2 & 7.8 \\
\hline Sum & 493 & 99 & 394 & 419.6 & 96.3 & 340.6 \\
\hline Average & 22.4 & 4.5 & 17.9 & 19.1 & 4.4 & 15.5 \\
\hline
\end{tabular}

\section{Discussion}

Our finding that installing HSR on freeways leads to increases in crashes is consistent with previous studies from the USA [48,49] and Austria [50], but in contrast with the results obtained in another study from the USA [19], two studies from Germany [51,52], a study from the United Kingdom [53], and one from France [23]. some of the differences in the results obtained may be attributed to differences in the driving culture between countries, while some of the differences may be due to the methods used to evaluate the safety impact. Most of the studies did not perform any before-after analysis, except one [23] that also used an empirical Bayes method.

It should be noted that the number of freeway travel lanes also has an effect on crash frequency in sites with HSR. When total crash numbers are compared, the largest increase is found for sites with 4(5) lanes (four lanes without HSR and five lanes with HSR), with an estimated increase of 45.0 crashes. On the other hand, a moderate increase is found for 2(3) lanes, with an estimated increase of 8.7 crashes, and even a small reduction is found in the case of 3(4) lanes, with an estimated decrease of 1.4 crashes. However, in terms of crash severity, $25.3 \%$ of the estimated increase in crashes on 2(3)-lane sections is serious crashes (those involving injuries and/or fatalities), while only $3.6 \%$ of the increase in 4(5)-lane sites consists of serious crashes. The finding from this study on the effect of the number of lanes on crash frequency is consistent with a previous study that found that the increase in accident rate in 2(3)-lane freeways to be higher than the increase in accident rate for 3(4)-lane freeways [50]. Thus, it is advised that HSR should be applied with caution to freeways with two travel lanes.

Moreover, further analysis of the results reveals a positive relationship between the length of the HSR and changes in crash frequencies. The estimated correlation coefficient between length and changes in total crashes (actual number of total crashes - expected number of total crashes) is positive and statistically significant $(r=0.468, p=0.028)$. Similarly, the estimated correlation coefficient between length and changes in serious crashes (actual number of serious crashes - expected number of serious crashes) is positive and statistically significant $(\mathrm{r}=0.591, p=0.004)$. These findings are consistent with previous studies on the safety effects of HSR $[22,49,50]$. The results are expected as an increase in freeway length increases exposure, which is a significant contributing factor to crash frequency. Also, more traffic flow disturbance is expected to occur with longer designs than with shorter designs, and consequently, traffic incidents will be more likely to occur. Therefore, we recommend that lengthy HSR should be avoided. 
On the other hand, further analysis of the results reveals no relationship between lane width and changes in the frequency of total crashes $(r=0.159, p=0.478)$, between lane width and changes in the frequency of serious crashes $(\mathrm{r}=-0.114, p=0.612)$, between shoulder width and changes in the frequency of total crashes $(r=0.175, p=0.436)$, and between shoulder width and changes in the frequency of serious crashes $(r=0.004, p=0.987)$. These results are in contrast with those obtained in previous studies $[32,33]$ that found a relationship between width values and crash occurrences. The results of this study may be due to small changes in the lane and shoulder widths for the sites included in this study.

\section{Conclusions}

HSR has been increasingly used in recent years as a more sustainable way to alleviate congestion and increase the efficiency of freeways in many countries. However, some engineers are concerned with their effect on safety. Moreover, several studies on the safety effects of HSR have produced mixed results. This study evaluates the safety effect of HSR by applying the EB (empirical Bayes) methodology to crash data from South Korea collected before and after HSR trials.

This study found that freeways with HSR experienced crashes more frequently, but most of the crashes were less severe. In terms of crash severity, a higher proportion of crashes (25.3\%) on 2(3)-lane sections were found to be serious (involving injuries and/or fatalities) compared to 4(5)-lane sections (3.6\%). Finally, a positive relationship was found between the length of the HSR and changes in crash frequencies. Hence, caution should be exercised when designing and implementing HSR to reflect the trade-off between improvements in efficiency and a reduction in safety. Also, HSR on lengthy freeways with 2(3)-travel lane configurations should be avoided.

Author Contributions: Conceptualization, J.C., S.K., S.J., R.T.; methodology, J.C., R.T., S.K., S.J., J.K., T.H.; formal analysis, J.C., R.T., S.J., J.K.; data collection, J.C., S.K., S.J., J.K.; writing-original draft preparation, J.C., S.K., S.J., J.K., T.H.; writing-review and editing, J.C., R.T., S.K.; project administration, J.C., S.J.; funding acquisition, J.C.

Funding: This work was supported by the 2016 Research Fund of the University of Seoul.

Conflicts of Interest: The authors declare no conflict of interest. The funders had no role in the design of the study; in the collection, analyses, or interpretation of data; in the writing of the manuscript, or in the decision to publish the results.

\section{References}

1. McCarthy, P.; Tay, R. Economic efficiency vs. traffic restraint: A note on the Singapore's area licensing scheme. J. Urban Econ. 1993, 34, 96-100. [CrossRef]

2. Cho, H. Traffic Congestion Costs; Korea Transport Institute: Seoul, Korea, 2014.

3. Hong, S.; Yun, J.; Kim, S. An estimation on traffic congestion cost based on VDS data. Transp. Technol. Policy 2015, 12, 13-18.

4. Kim, S.; Yoon, I.; Park, J.; Park, I.; Cheon, S.; Kim, G.; An, H. Estimation of the expressway traffic congestion cost using vehicle detection system data. Int. J. Highw. Eng. 2016, 18, 99-107. [CrossRef]

5. Jeong, Y.; Kim, Y.; Lee, S. Integrated traffic management strategy on expressways using mainline metering and ramp metering. J. Korea Inst. Intell. Transp. Syst. 2013, 12, 1-11. [CrossRef]

6. Li, Y.; Chow, A.; Cassel, D. Optimal control of motorways by ramp metering, variable speed limits, and hard shoulder running. Transp. Res. Rec. 2014, 2470, 122-130. [CrossRef]

7. Shim, S.; Lee, H.; Lee, K.; Choi, K. Classification method of congestion change type for efficient traffic management. Int. J. Highw. Eng. 2014, 16, 127-134. [CrossRef]

8. Chun, P.; Fontaine, M. Evaluation of the Impact of the I-66 Active Traffic Management System; Final Report; Virginia Transportation Research Centre: Charlottesville, VA, USA, 2016.

9. Ma, J.; Hu, J.; Hale, D.; Bared, J. Dynamic hard shoulder running for traffic incident management. Transp. Res. Rec. 2016, 2554, 120-128. [CrossRef]

10. ITS International. Traffic Monitoring and Hard Shoulder Running; ITS International: Warrington, UK, 2013.

11. Holstein, D. Hard Shoulder Running; Ohio Department of Transportation: Columbus, OH, USA, 2016. 
12. Guerrieri, M.; Mauro, R. Capacity and safety analysis of hard-shoulder running (HSR). A motorway case study. Transp. Res. Part A 2016, 92, 162-183. [CrossRef]

13. KEC. Korea Expressway Corporation State Audit; Korea Expressway Corporation: Seoul, Korea, 2012.

14. KSRE. Planning Study for Introduction of New Paradigm of Road Pavement; Korean Society of Road Engineers: Seoul, Korea, 2015.

15. KEC. In-Office Material for Introducing Hard Shoulder use in Freeways; Korea Expressway Corporation: Seoul, Korea, 2005.

16. KOROAD. A Study on the Establishment of Active Traffic Management System; Korea Road Traffic Authority Traffic Science Institute: Seoul, Korea, 2013.

17. AASHTO. Highway Safety Manual; American Association of State Highway and Transportation Officials: Washington, DC, USA, 2010.

18. Geistefeldt, J. Operational experience with temporary hard shoulder running in Germany. Transp. Res. Rec. 2012, 2278, 67-73. [CrossRef]

19. Kononov, J.; Hersey, S.; Reeves, D.; Aller, B. Relationship between freeway flow parameters and safety and its implications on hard shoulder running. Transp. Res. Rec. 2012, 2280, 10-17. [CrossRef]

20. Samoili, S.; Dimitrios, E.; Constantinos, A.; André-Gilles, D. Short-term lane flow distribution forecasting in hard shoulder running freeways. In Proceedings of the International Symposium on Recent Advances in Transport Modeling, Kingscliffe, Australia, 21-23 April 2013.

21. KEC. Traffic Crash Statistics Data 2006-2016; Korean Expressway Corporation: Seoul, Korea, 2016.

22. Aron, M. Two French hard-shoulder running operations: Some comments on effectiveness and safety. In Proceedings of the 13th International IEEE Annual Conference on ITS, Funchal, Portugal, 19-22 September 2010.

23. Aron, M.; Seidowsky, R.; Cohen, S. Safety impact of using the hard shoulder during congested traffic: The case of a managed lane operation on a French urban motorway. Transp. Res. Part C Emerg. Technol. 2013, 28, 168-180. [CrossRef]

24. Bhouri, N.; Aron, M.; Scemama, G. Travel time reliability with and without the dynamic use of hard shoulder: Field assessment from a French motorway. J. Traffic Transp. Eng. 2016, 3, 520-530. [CrossRef]

25. Charlton, S. Perceptual and attentional effects on drivers' speed selection at curves. Accid. Anal. Prev. 2004, 36, 877-884. [CrossRef] [PubMed]

26. Martens, M.; Fox, M. Do familiarity and expectations change perception? Drivers' glances and response to changes. Transp. Res. Part F 2007, 10, 476-492. [CrossRef]

27. Colonna, P.; Intini, P.; Berloco, N.; Ranieri, V. The influence of memory on driving behavior: How route familiarity is related to speed choice. An on-road study. Saf. Sci. 2016, 82, 456-468. [CrossRef]

28. Bajikar, S.; Gorjestani, A.; Simpkins, P.; Donath, M. Evaluation of in-vehicle GPS-based lane position sensing for preventing road departure. In Proceedings of the ITS Conference, Boston, MA, USA, 17-23 May 1997.

29. Brookhuis, K.; De Waard, D.; Janssen, W. Behavioural impacts of advanced driver assistance systems-an overview. Eur. J. Transp. Infrastruct. Res. 2001, 1, 245-253.

30. Charlton, S. The role of attention in horizontal curves: A comparison of advance warning, delineation, and road marking treatments. Accid. Anal. Prev. 2007, 39, 873-885. [CrossRef] [PubMed]

31. Anastasopoulos, P.; Mannering, F. A note on modeling vehicle accident frequencies with random-parameters count models. Accid. Anal. Prev. 2009, 41, 153-159. [CrossRef] [PubMed]

32. Urbanik, T. Factors affecting selection of lane width and shoulder width on urban Freeways. Transp. Res. Rec. 1994, 1445, 125.

33. Lim, J.; Lee, S.; Kim, J.; Kim, J. A Development of Traffic Accident Estimation Model by Random Parameter Negative Binomial Model: Focus on Multilane Rural Highway. J. Korean Soc. Transp. 2014, 32, $662-674$. [CrossRef]

34. Smiley, A. Human Factors in Traffic Safety; Lawyers and Judges Inc.: Tucson, AZ, USA, 2016.

35. Abdel-Aty, M.; Radwan, A. Modeling traffic crash occurrence and involvement. Accid. Anal. Prev. 2000, 32, 633-642. [CrossRef]

36. Chin, H.; Quddus, M. Applying the random effect negative binomial model to examine traffic crash occurrence at signalized intersections. Accid. Anal. Prev. 2003, 35, 253-259. [CrossRef]

37. Chang, L. Analysis of freeway crash frequencies: Negative binomial regression versus artificial neural network. Saf. Sci. 2005, 43, 541-557. [CrossRef] 
38. Anastasopoulos, P.; Mannering, F.; Shankar, V.; Haddock, J. A study of factors affecting highway crash rates using the random-parameters tobit model. Accid. Anal. Prev. 2012, 45, 628-633. [CrossRef] [PubMed]

39. ITE. Manual of Transportation Engineering Studies, 2nd ed; Institute of Transportation Engineers: Washington, DC, USA, 2010.

40. Hauer, E. Observational Before-After Studies in Road Safety. Estimating the Effect of Highway and Traffic Engineering Measures on Road Safety; Emerald Group Publishing Limited: Bingley, UK, 1997.

41. Hauer, E.; Harwood, D.; Council, F.; Griffith, M. Estimating safety by the Empirical Bayes method: A tutorial. Transp. Res. Rec. 2002, 1784, 126-131. [CrossRef]

42. Zou, Y.; Ash, J.; Park, B.; Lord, D.; Wu, L. Empirical Bayes estimates of finite mixture of negative binomial regression models and its application to highway safety. J. Appl. Stat. 2018, 45, 1652-1669. [CrossRef]

43. Wang, J.; Abel-Aty, M.; Wang, L. Examination of the reliability of the crash modification factors using empirical Bayes method with resampling technique. Accid. Anal. Prev. 2018, 104, 96-105. [CrossRef] [PubMed]

44. Huang, H.; Chin, H.; Haque, M. Empirical evaluation of alternative approaches in identifying crash hot spots: Naive ranking, empirical Bayes, and full Bayes methods. Transp. Res. Rec. 2009, 2103, 32-41. [CrossRef]

45. Hoye, A. Safety effects of section control-An empirical Bayes evaluation. Accid. Anal. Prev. 2015, 74, 169-178. [CrossRef]

46. Persaud, B.; Lyon, C. Empirical Bayes before-after safety studies: Lessons learned from two decades of experience and future directions. Accid. Anal. Prev. 2007, 39, 546-555. [CrossRef]

47. Elvik, R.; Ulstein, H.; Wifstad, K.; Syrstad, R.; Seeberg, A.; Gulbrandsen, M.; Welde, M. An Empirical Bayes before-after evaluation of road safety effects of a new motorway in Norway. Accid. Anal. Prev. 2017, 108, 285-296. [CrossRef] [PubMed]

48. Kellermann, K. Experience of using the hard shoulder to improve traffic flow. Traffic Eng. Control 2000, 41, 412-414.

49. Bauer, K.; Harwood, D.; Hughes, W.; Richard, K. Safety Effects of Narrow Lanes and Shoulder-Use Lanes to Increase Capacity of Urban Freeways. Transp. Res. Rec. 2004, 1897, 71-80. [CrossRef]

50. Berger, W.; Maurer, P. Emergency bays versus emergency lanes on motorways-A cost benefit analysis. In Proceedings of the 10th International Conference on Traffic Safety on Two Continents, Mälmo, Sweden, 20-22 September 1999.

51. Lemke, K. Safety Effects of Hard Shoulder Conversion; Reports of the German Federal Highway Research Institute; German Federal Highway Research Institute: Bergisch Gladbach, Germany, 2007.

52. Geisterfeldt, J. Temporary hard shoulder use in Hesse-Effects on traffic flow and road safety. In Proceedings of the 16th ITS World Congress and Exhibition on Intelligent Transport Systems and Services, Stockholm, Sweden, 21-25 September 2009.

53. Unwin, P. A Shoulder to Rely On. ITS Int. 2011, 17, 39-42. 